\title{
Electrotechnologies applied to microalgal biotechnology - Applications, techniques and future trends
}

\author{
Pedro Geada ${ }^{a}$,*, Rui Rodrigues ${ }^{\mathrm{a}}$, Luís Loureiro ${ }^{\mathrm{a}}$, Ricardo Pereira ${ }^{\mathrm{a}}$, Bruno Fernandes ${ }^{\mathrm{a}}$, \\ José A. Teixeira ${ }^{\mathrm{a}}$, Vítor Vasconcelos ${ }^{\mathrm{b}}$, António A. Vicente ${ }^{\mathrm{a}}$ \\ ${ }^{\text {a }}$ CEB-Centre of Biological Engineering, University of Minho, Braga Portugal \\ ${ }^{\mathrm{b}}$ CIIMAR/CIMAR - Interdisciplinary Centre of Marine and Environmental Research and Department of Biology, Faculty of Sciences, University of Porto, Porto, Portugal
}

\section{A R T I C L E I N F O}

\section{Keywords:}

Electric fields

Microalgae

Processing

Energy

Biomass

Process intensification

\begin{abstract}
A B S T R A C T
Electrotechnologies are based on the direct application of an external electric field through a given semi-conductive material. These technologies are part of a wide range of biotechnological processes, considered costeffective and environmentally-friendly in view of the less intensive use of non-renewable resources and high levels of energetic efficiency. In this regard, electrotechnologies are a promising processing tool to overcome some of the microalgae's exploitation limitations. The application of electric field-based techniques can cover upstream (i.e. electroporation for genetic transformation, inactivation of culture contaminants, and improvement of growth kinetics) and downstream processes (e.g. harvesting and extraction methods). Pulsed electric fields (PEF) and moderate electric fields (MEF), targeted at microalgae cellular permeabilization and subsequent extraction of valuable compounds, count with a substantial body of fundamental research which puts them on the front row to become mainstream techniques in a near future. This review provides comprehensive knowledge systematization of the current status of the direct application of these techniques on microalgal biotechnology, as wells as future trends and challenges regarding developments in electrotechnologies to be applied to microalgae industrial exploitation.
\end{abstract}

\section{Introduction}

\subsection{Microalgae and its applications}

Microalgae are an extremely diverse group of microscopic organisms, representing one of the oldest forms of life on Earth [1]. These microorganisms are defined as primitive plants (thallophytes) - not presenting roots, stems and leaves - comprising unicellular plants (Chlorophyta), bacteria (Cyanobacteria), diatoms (Chromalveolata) and protists (Chromista) that can be found mostly in marine and freshwater environments [2-4]. In contrast with higher plants, microalgae do not need a vascular system for nutrient transport (absorbing nutrients directly), which confers a great advantage in terms of energy efficiency $[5,6]$. According to the nutritional requirements of microalgae, they can be classified as autotrophs or heterotrophs depending if the source of carbon used for growth is inorganic mineral ions or organic compounds, respectively [5] - Fig. 1. The great versatility displayed by microalgae allowed them to thrive on a wide range of environments across the globe including under extreme conditions of temperature, $\mathrm{pH}$, light intensity and salinity [7].

Despite the limitless commercial potential of microalgae (see Fig. 1), these microorganisms remain greatly unexplored since several million of species are estimated to exist [8-10]. The starting point on microalgae use by humans occurred about 2000 years ago when the Chinese started using them as a food source.

In fact, due to their high nutritional value, especially in terms of proteins, lipids, and carbohydrates [15], microalgae are still extensively used as a source of food in Asiatic countries [16,17]. Chlorella, Spirulina, Haematococcus and Dunaliella represent the majority of the market, which can be commercialized in tablet, capsule, liquid and powder forms or added to pasta, snacks and drinks as nutritional supplements or natural dyes $[4,16,18,19]$. When ingested, the high-protein content microalga Chlorella was found to enhance the growth of intestinal Lactobacillus, while Spirulina sp. and Dunaliella sp. can act as potent anticancer agent due to their carotenoids content $[20,21]$. In spite of the significant efforts for leveraging microalgae as human food, linking

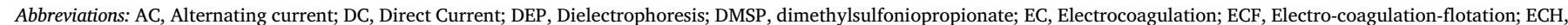

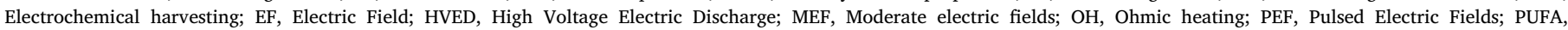
Polyunsaturated fatty acid

* Corresponding author.

E-mail address: pedrogeada@ceb.uminho.pt (P. Geada). 


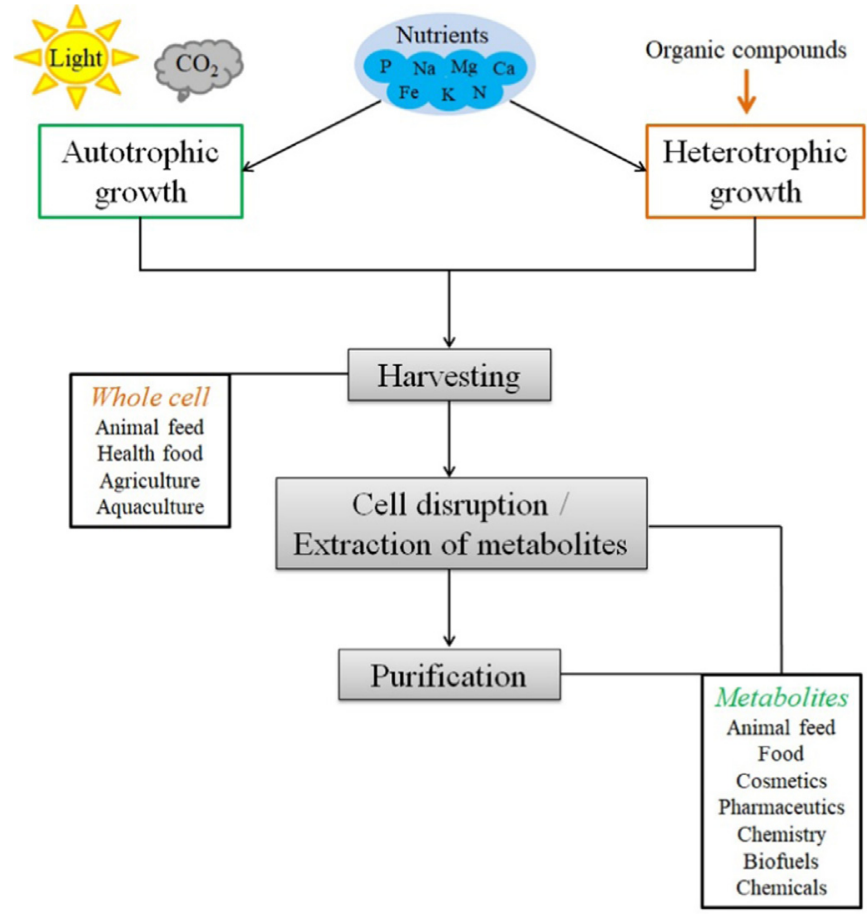

Fig. 1. Microalgae production steps and potential applications.

them to "healthy" food, the high production costs and the strict food safety regulations have shown to be restrictive to this mind-set shift. Consequently, microalgae cultures have been mostly used as feed additives in aquaculture food chain (e.g. larvae and juvenile molluscs, penaeid prawn, and crustaceans, as well as fish) improving immune system response, fertility and weight control in addition to promote a healthier skin (e.g. more colourful) and lustrous coat $[9,22,23]$. Besides aquaculture feeding, Spirulina and Chlorella are used in food diets of domestic animals [11]. As an example, eggs can be enriched in omega-3 fatty acids by feeding hens with microalgae containing high percentage of PUFAs [9,22]. Nowadays, besides food and feed applications, microalgae are utilized in chemical, biofuels, pharmaceutical, and cosmetics sectors, either in whole-cell form or through their functional compounds [12-14,22].

To reduce microalgae production costs and therefore stimulate its generalized commercialization, a strategy might be implemented combining algal growth in open or closed systems with $\mathrm{CO}_{2}$ fixation (i.e. from exhaust gases originated by fossil fuel combustion) and/or wastewater treatment processes, supressing nutritional needs of microorganisms $[5,12,14,24]$. This will not only contribute to control issues involving greenhouse gases emissions (namely $\mathrm{CO}_{2}$ ) and contaminants removal from wastewater, but also generate economic value utilizing wastes or by-products from other industrial processes [7]. Thus, besides ensuring environmental sustainability, such production scheme is also suitable to use microalgae cells as raw material to produce not only a wide range of biofuels (e.g. biodiesel, bioethanol), but also high added-value bioactive compounds (e.g. proteins, pigments, vitamins, antioxidants) $[5,11,12,25,26]$. Taking advantage of the ability of a number of microalgae for fixing atmospheric nitrogen, namely cyanobacteria species, these microorganisms are commonly utilized in agriculture as biofertilizers. By fixing nitrogen, microalgae improve soil fertility and its physico-chemical properties leading to higher plant growth yields. Moreover, the use of microalgae as biofertilizer entails another benefit for plants which consists on the production of several growth-promoting substances like vitamin $B_{12}$ [4]. A different method for using microalgae as biofertilizers lies on subjecting them to a pyrolysis process resulting in the formation of solid charcoal residue (i.e. biochar) [22].

\subsection{Metabolites with commercial interest}

Depending on the type of microalgae used, numerous bioactive

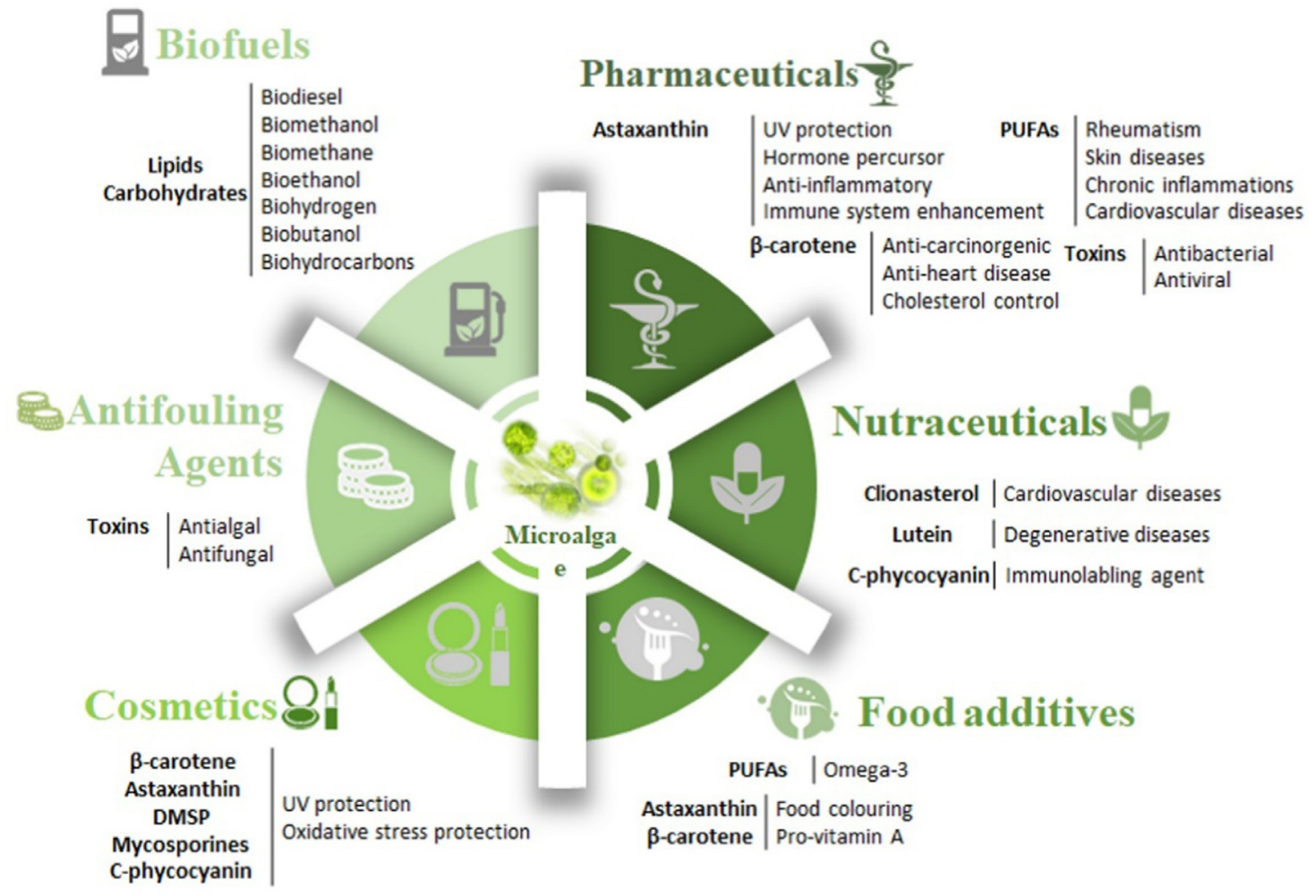

Fig. 2. Microalgae metabolites of interest and potential application areas. 
molecules including pigments, antioxidants, polysaccharides, fatty acids, and vitamins can be obtained for commercial purpose in different industrial segments such as pharmaceuticals, cosmetics, nutraceuticals, functional foods, antifouling agents and biofuels - Fig. 2 $[4,5,12,23,25,27,28]$.

Microalgae extracts from species such as Chlorella vulgaris, Dunaliella salina, Spirulina platensis and Nannochloropsis oculata, are frequently part of the composition of cosmetics like face and skin care products with anti-ageing, refreshing/regenerating, and anti-irritant properties acting as thickening, water-binding and antioxidant agents $[4,29]$. $\beta$ carotene, astaxanthin, dimethylsulfoniopropionate (DMSP), mycosporines or mycosporine-like amino acids, and C-phycocyanin are some of the compounds used in cosmetics mainly due to their protection against UV radiation and oxidative stress which is responsible for several diseases and ageing $[22,23]$. Astaxanthin and $\beta$-carotene, for example, are used not only as additive in cosmetics but also as food colouring or as source of pro-vitamin A [9,30-32]. C-phycocyanins, on the other hand, are promising candidates to be applied in immunolabeling experiments as labels for antibodies, receptors or other biomolecules since they have shown to be powerful and highly sensitive fluorescent reagents [22]. At pharmaceutical level, there is also a considerable number of (potential) applications involving a huge quantity of bioactive compounds generated by microalgae. Astaxanthin can act as immune system enhancement, hormone precursor, and has anti-inflammation properties that might have a positive effect on human health, while $\beta$-carotene is well known for its effective control over cholesterol as well as anti-carcinogenic and anti-heart disease activity [4,32]. Regarding the therapeutic effect of clionasterol (a sterol isolated from Spirulina sp.) and lutein (an abundant carotenoid in Muriellopsis sp.), they were found to prevent or treat cardiovascular and degenerative diseases, respectively $[20,23]$. Due to the large variety of PUFAs produced by microalgae, their potential applications cover a wide range of diseases such as rheumatism, skin diseases and inflammation of the mucosa of the gastrointestinal tract (chronic inflammations) by applying these molecules in prophylactic and therapeutic treatments. Furthermore, PUFAs are thought to play an important role on cardio-circulatory and coronary heart diseases, as well as on treatment of atherosclerosis, hypertension, cholesterol and cancer [23]. Additionally, more attention has been given to microalgal intracellular and extracellular metabolites, namely toxins produced by several strains of cyanobacteria. These toxins and other metabolites present a wide range of biological activities including antialgal, antibacterial, antifungal and antiviral activity which are certainly useful from the pharmaceutical point of view [33-36]. In spite of the countless aforementioned applications and properties, the main interest on microalgae still arises from the possibility of using them as feedstock for the production of third generation biofuels. The accumulation of large amounts of high quality lipids and carbohydrates places microalgae as very promising potential candidates to become the basis of the production of a great variety of renewable fuels like biodiesel, biomethanol, biomethane, bioethanol, biohydrogen, biobutanol, and biohydrocarbons $[5,6,23]$. The several advantages of the use of microalgae can be summarized as follows: $i$ ) quicker, more efficient and sustainable growth when compared to biodiesel feedstocks of agricultural origin (e.g. soya, palm seed, rapeseed), with higher productivity yields $[5,37,38]$; ii) reduced or even inexistent competition for arable soil and traditional food market for human consumption as well as the possibility of performing continuous cultures throughout the entire year regardless of seasonal weather changes [4,5,23]; iii) potential integration of microalgal growth in environmental problemsolving strategies as the removal of $\mathrm{CO}_{2}$ and contaminants from flue gases and wastewater, respectively [5,39]; and $i v$ ) production of a large range of valuable co-products and by-products (besides lipids and carbohydrates utilized for biofuels production) that can be harnessed by other biotechnological areas.

\subsection{Needs in microalgae bioprocessing}

The major hurdles that need to be overcome in order to increase the number of microalgae strains cultivated at large scale are high production costs - mainly due to the amount of energy required during growth and downstream steps - and high initial investment $[7,12,40]$. Consequently, some authors suggest that microalgae production might become economically feasible at industrial scale if a multiple product exploitation strategy is applied through the biorefinery concept $[7,22,38]$. By doing this, the combined market value of these products could surpass the costs involved in production process and therefore maximize microalgae biomass exploitation [41]. However, conventional extraction methods like homogenization, heating, or osmotic shock are commonly performed and fully tested with the purpose of maximizing the collection of one specific product only, even if it represents destruction or damage and subsequent loss of all the other high-added value metabolites that may be present. Thus, mild, inexpensive, low energy consumption and effective techniques, such as pulsed electric fields (PEF), low or moderate electric fields (MEF), ultrasounds, and eventually the use of green solvents, such as ionic liquids and eutectic solvents, must be developed, optimized and synergistically combined, not only to maintain the properties of all the extracted products but also to promote a sustainable and more environmentfriendly approach [38]. This review will describe and discuss the potential applications of electric fields (EFs) processing at different stages of the microalgae production process.

\section{Electric fields processing}

The growing interest on the effects of EFs processing in biological systems along with the need for more efficient and cost-effective technologies are driving the interest in research and application of electrotechnologies. These technologies consist on the application of an external EF with a defined technological purpose. Despite the technological potential of these electric-based technologies has been long recognized, operational problems and the lack of fundamental knowledge about the processes delayed their application at a commercial scale [42-44]. Nevertheless, much effort has been put into the development and optimization of these technologies resulting on matured and reliable processes with high efficiencies, which is particularly true in the case of extraction applications [45]. It was only during the 1970's and 1980 's that technological advances made electrotechnologies technically viable [46]. Nowadays, electrotechnologies have branched in novel methods and applications, finding potential or effective use in all stages of microalgae production (Table 1).

The presence of an electrical field may result in different outcomes and practical applications depending on its inherent electrical properties - i.e. EF intensity, type of electrical waveform and electrical frequency, treatment duration, among others [47]. Certainly, one of the EF effects that drives more attention is electroporation. The exposure of a cell to an EF causes a transmembrane potential in the cellular membrane. The effectiveness of the EF is the result of the field strength applied and the cell radius, meaning the smaller the cell radius, the higher the external field to be applied in order to achieve the same effect [48]. When the transmembrane potential exceeds some threshold value (i.e. $0.2-1.0 \mathrm{~V}$ ), the EF promotes electro-permeabilization of the membrane. This effect can be temporary or permanent and may result on an increased flux of compounds through the membrane, cell damage and destruction [49]. In Fig. 3a general perspective of the electroporation phenomenon is represented.

Another consequence of exposure to $\mathrm{EF}$ is heat generation in the medium through the Joule effect. In this process, commonly referred as ohmic heating $(\mathrm{OH})$, heat is produced directly within the material itself, as the electric current passes through the semi-conductive material. Heating is due to friction occurring during molecular agitation provoked by the motion of charged molecules within the material. The fast, 


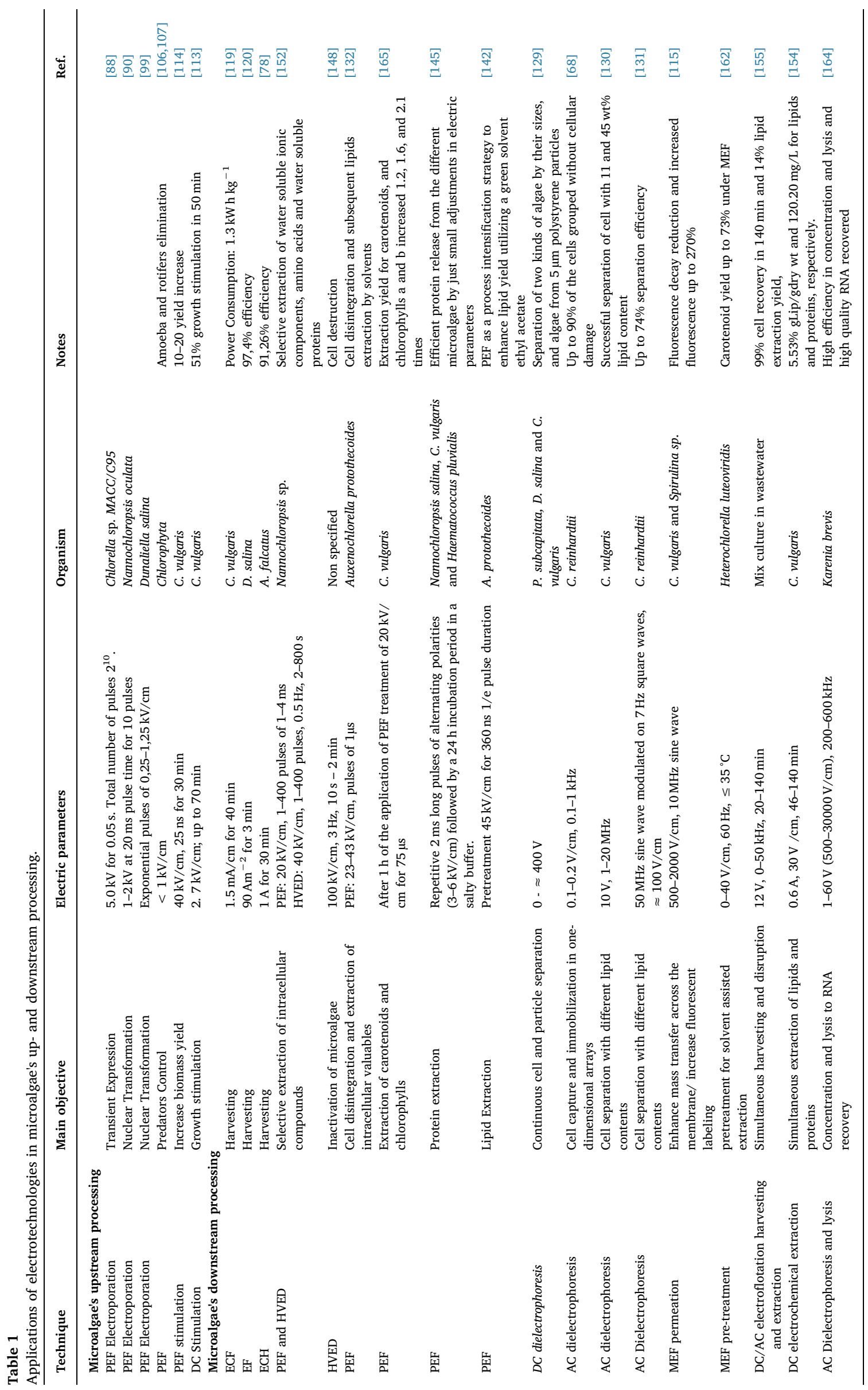




\section{Reversible electroporation}

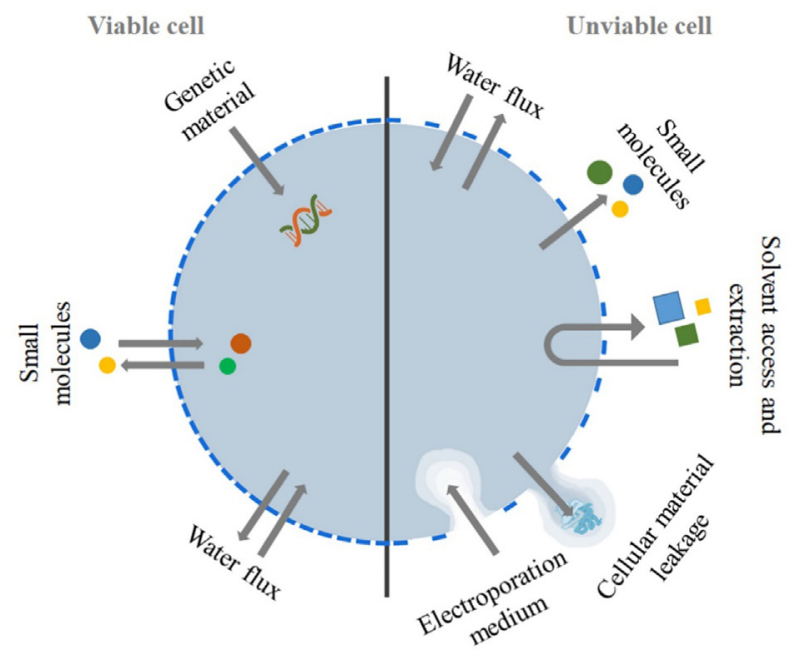

Fig. 3. Diagram representing different electroporation levels and their consequences.

homogenous and energetically efficient ( $>90 \%$ ) heating provided by the Joule effect has found interest in aseptic processing of liquid-particulate mixtures, processing residues and extraction processes [46]. Cells and particularly microalgae, as almost every particle occurring in Nature, have an inherent electrical charge. These charges lead to the occurrence of electro-kinetic phenomena under the presence of an EF. Electrophoretic movements, under the presence of a continuous EF, or dielectrophoresis motion of dielectric particles under a non-uniform EF, offers the possibility to electrically control the trapping, focusing, translation or fractionation of particles [50].

Despite of these effects being inherent to the presence of an EF, EF techniques should rely on a particular set of parameters and specificities in order to be effective and achieve practical relevance. Hence, the categorization of these technologies depends on the parameters set for the EF applied and technical specificities involved, more than on the EF itself. Some of the criteria used to classify different techniques are the nature of the electric flow (i.e. alternating or direct and pulsed or nonpulsed), the EF strength $(\mathrm{V} / \mathrm{cm})$, the extension of heat dissipation, among others. These parameters influence the effects induced, the classification of the techniques, and are crucial to define design and operational requirements of the equipment. In this section, the main electrotechnologies applied to microalgae production and processing will be reviewed and defined according with their operational parameters and effective or potential applications. An overview of electrotechnologies general setups and specifications is presented in Fig. 4.

\subsection{Pulsed Electric Fields}

Pulsed Electric Fields (PEF) involve the application of electrical pulses usually at high voltages ( $\mathrm{kV}$ range) and short durations (micro or nano-seconds) to a product placed between two electrodes [51].

The fundamental principle in PEF application is electroporation or electropermeabilization, where a transmembrane potential is induced by means of an externally applied EF of enough strength to cause enlargement of existing pores or the creation of new ones in the lipid bilayer, thus increasing cells' plasma membrane conductivity and permeability. This effect may be temporary or permanent and also affect intracellular membrane structures $[52,53]$.

Some critical factors can affect PEF application and efficiency, specifically EF strength, pulse shape, treatment time and polarity, temperature, and target product characteristics [54]. It is generally recognized that the increase of the $\mathrm{EF}$ strength increases permeabilization effects, going from temporary electroporation from which the
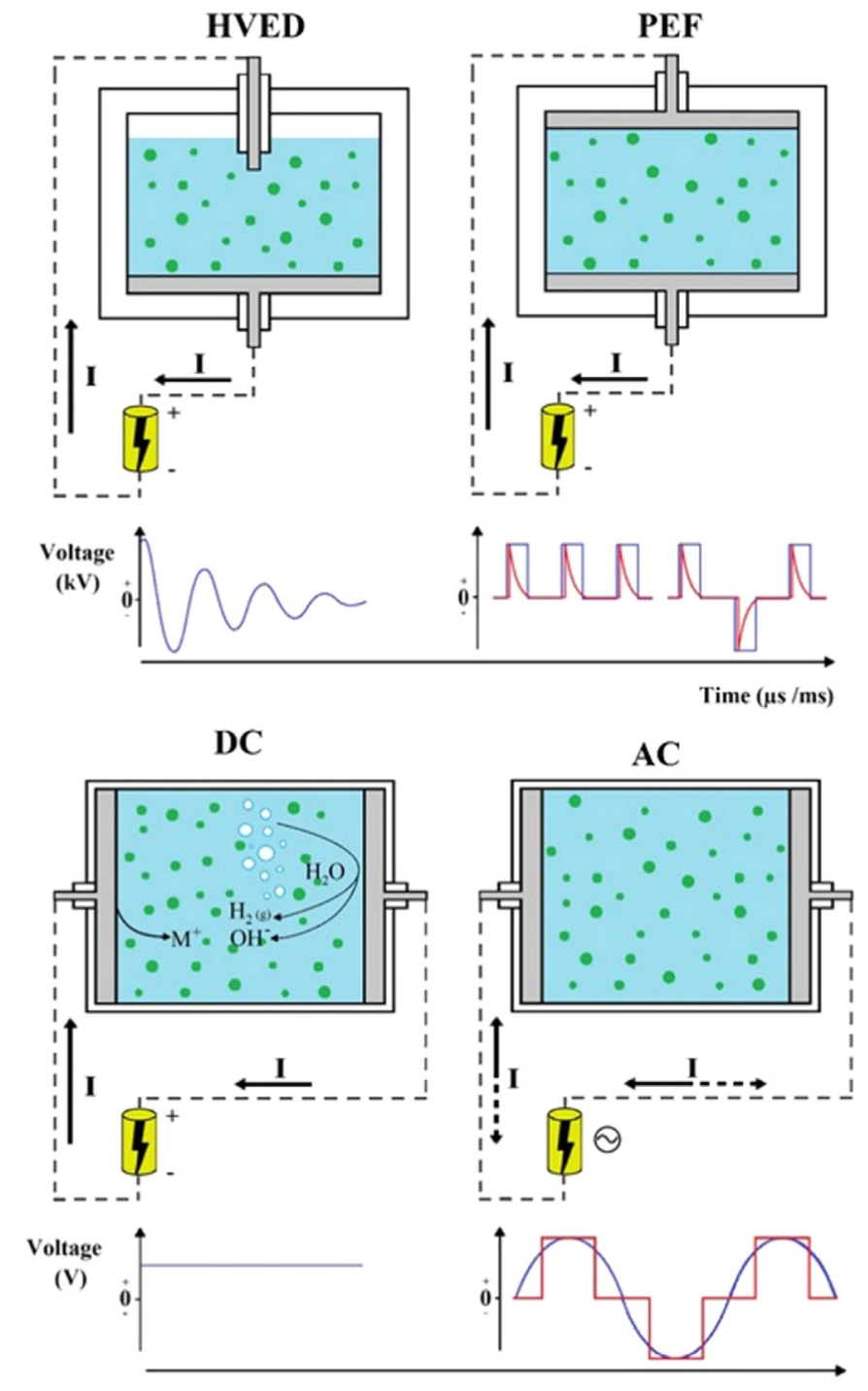

Time (s)

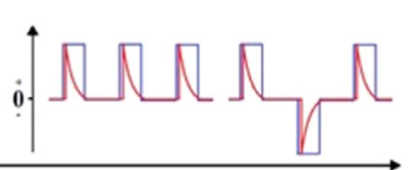

Time ( $\mu \mathrm{s} / \mathrm{ms})$

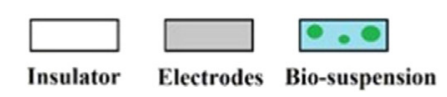

Fig. 4. Diagrams of general setups and specifications involving electrotechnologies for High Voltage Electric Discharges (HVED), Pulsed Electric Fields (PEF), Direct Current (DC) and Altering Current (AC) applications (adapted from Poojary et al. [79]).

cell recovers to original state, to a permanent permeabilization or even, in extreme cases, cell lysis [52].

An important factor to characterize PEF systems is the pulse waveform, being the EF usually applied in the form of exponentially decaying or square waves. Square waves are more energetic due to a more extended peak voltage in comparison to exponential pulses. Nevertheless, the exponentially decaying waves are easier to generate compared to the more challenging square wave system. Advances in solid-state pulse generators turned square wave application more feasible, still involving higher costs $[55,56]$. Electrolytic reactions leading to product deterioration and electrode corrosion, as well as electrophoretic deposition, may take place during mono-polar PEF treatments. In order to minimize these problems, bipolar pulses are more attractive in spite of being more difficult to generate [57].

Pulse width or duration and number of pulses are commonly used as independent factors to characterize PEF treatments, yet its independent relation with the efficiency of the process is still unclear. There are 
some evidences that longer pulses produced increased effects in biomass disintegration and microbial inactivation [58,59]. In contrast, other authors prefer defining treatment time as a key factor, being this the product of the number of pulses and pulse duration. In fact, it has been reported that in the inactivation of Listeria and Salmonella, the treatment efficiency is maintained after the same treatment time, regardless of the width or number of pulses applied [54,60]. Along with the EF strength, the increase of treatment time leads to higher treatment efficiency; nevertheless, it also increases energy consumption and the risk of heat generation (ohmic heating).

PEF is supposed to be essentially a non-thermal process, in spite of temperature elevation occurring usually from a few degrees to dozens. Still, the temperature is frequently kept below denaturation levels and energy requirements are noticeably lower than, for instance, equivalent thermal inactivation processes [56,57].

Although PEF process shows successful results in laboratory tests and great potential in bioprocessing, applying PEF on a large scale presents many unresolved engineering problems and requires further investigation and maturation. Nonetheless, PEF technology is no doubt the leading and most significant electrotechnology in successful applications and literature reports.

\subsection{High Voltage Electric Discharge}

Another form of pulsed EF application is the High Voltage Electric Discharge (HVED). This process involves a direct high energy release into a liquid medium causing a plasma channel formation by the HVED [61]. HVED consists of an electrical breakdown in water and its associated secondary side-events, which can include pressure shock waves of high amplitude, cavitation, formation of radicals, among others [62]. Electroporation due to the high strength EF is significant, although cell damage and even destruction may be induced mostly by the associated mechanical stress of the process. This application has demonstrated to be successful in extraction of compounds of interest and cell inactivation (Table 1). However, its requirements both for the pulse generators and regarding toughness of the system and its materials still impair the practical application of the technique $[63,64]$.

\subsection{Alternating current}

Alternating current (AC) is characterised by an electric waveform whose voltage periodically alternates its polarity. Usually referred as Moderate Electric Fields (MEF) applications, an EF of relatively low intensity (arbitrarily defined between 1 and $1 \times 10^{3} \mathrm{~V} / \mathrm{cm}$ ) and generally in a form of sinusoidal wave is applied [65]. Within the MEF field intensity range, several EF related effects have been described, such as permeabilization of cellular membrane, microbial inactivation, cells destruction and electrokinetic movement induction [65-68]. The EF strength is for sure an important parameter; however, using lower intensity fields for longer periods (keeping the energy input) has demonstrated to be equally effective in high and low energetic EF applications [54,69]. EF frequency is a key parameter in MEF application. The use of high frequencies (i.e. $>17 \mathrm{kHz}$ ) effectively eliminates the electrochemical reactions that otherwise could lead to electrode degradation/corrosion and consequent product contamination [70]. The application of frequencies on the $\mathrm{kHz}-\mathrm{MHz}$ range has influence on the dielectric properties of materials and may induce dielectrophoretic movements [71]. On the other hand, the utilization of low frequencies, despite of originating undesired electrochemical effects, usually demonstrates higher efficiency on the permeabilization of biological tissues [67]. The electrochemical phenomena (i.e. release of radicals and metal oxides from the electrodes, gas formation and bubbling) involved in low frequency EF application may be useful in electrocoagulation and/or electroflotation applications. Nonetheless, the effectiveness of MEF range techniques, particularly in cell permeabilization, seems closely related to the correct tuning of operational parameters, specific of the type of cell used [67,72-74].

The particular case of $\mathrm{OH}$ application has proven MEF technological potential, being commercially available for over 30 years. This thermal processing technology results in a uniform transmission of thermal energy, extremely rapid heating rates and high energetic efficiencies (frequently $>95 \%$ ) [75]. During the application of $\mathrm{OH}$ as a thermal pasteurization or sterilization technique, the electro-permeabilization due to the presence of $\mathrm{EF}$ has been demonstrated to increase microorganism inactivation, improving the process efficiency and even allowing to obtain equivalent effects at lower temperatures in comparison to a conventional thermal treatment. Its inactivation effects have actually been demonstrated at room temperature [65], thus indicating that not only temperature, but also electricity, are responsible for cell inactivation. The recognized electro-permeabilization effects, along with the fast and efficient heating, place $\mathrm{OH}$ on the frontline for thermal-assisted extraction treatments.

Dielectrophoretic movements caused on dielectric particles by the presence of a non-uniform EF are usually limited to small distances and require relatively high EF strengths. This imposes some boundaries in its applications, and suggests that this technique could also be applied in the fast-developing field of microfluidics [68]. Here, the particle displacement required is very small and EF strength at a length scale comparable to particle size can be generated at relatively low voltages. This drastically increases the process efficiency, reducing power requirements, and helps solving other problems such as excessive heating and electrode corrosion.

\subsection{Direct current}

Direct current (DC) can be defined as the unidirectional flow of electric charge through two electrodes: the negatively charged (cathode) and the positively charged (anode). A direct consequence of this unidirectional flow of charges is the electrophoretic movement of charged particles towards the opposite polarity electrode. With the polarization of the electrodes, electrochemical reactions may take place, particularly electro-oxidation of the electrodes and electrolysis of water, leading to electrode corrosion and bubbling [76].

The electrophoretic movement induced by a DC offers, in theory, the possibility of concentrating and separating cells from the culture medium [77]. EF strength is a relevant factor in the process since it affects particles' movement rate and, when sufficiently high, may cause permeabilization. However, the EF strength to be applied is limited by several factors impairing the aforementioned effects. High energy requirements, excessive heat deposition and low durability of the electrodes are the main factors limiting DC applications to electro-kinetic separation [47]. The occurrence of electrochemical reactions can be exploited in the process of microalgae harvesting since cell coagulation can be induced by ions released from the electrodes (usually aluminium or iron) as they suffer oxidation. After the process of electrocoagulation takes place, the flocs formed are then raised to the surface as the bubbles formed by the water hydrolysis cause flotation $[77,78]$.

\section{Application of electric technologies to microalgae biotechnology}

EF-based technologies in microalgae processing can cover from upstream (i.e. electroporation for genetic transformation, inactivation of culture contaminants, improvement of growth kinetics) to downstream processes (e.g. harvesting and extraction methods) - Fig. 5. The following sections will address the current status of the direct application of these techniques on microalgae biotechnology.

\subsection{Upstream applications}

\subsubsection{Electroporation for genetic transformation}

The increased interest in microalgae as a natural source of bioactive 


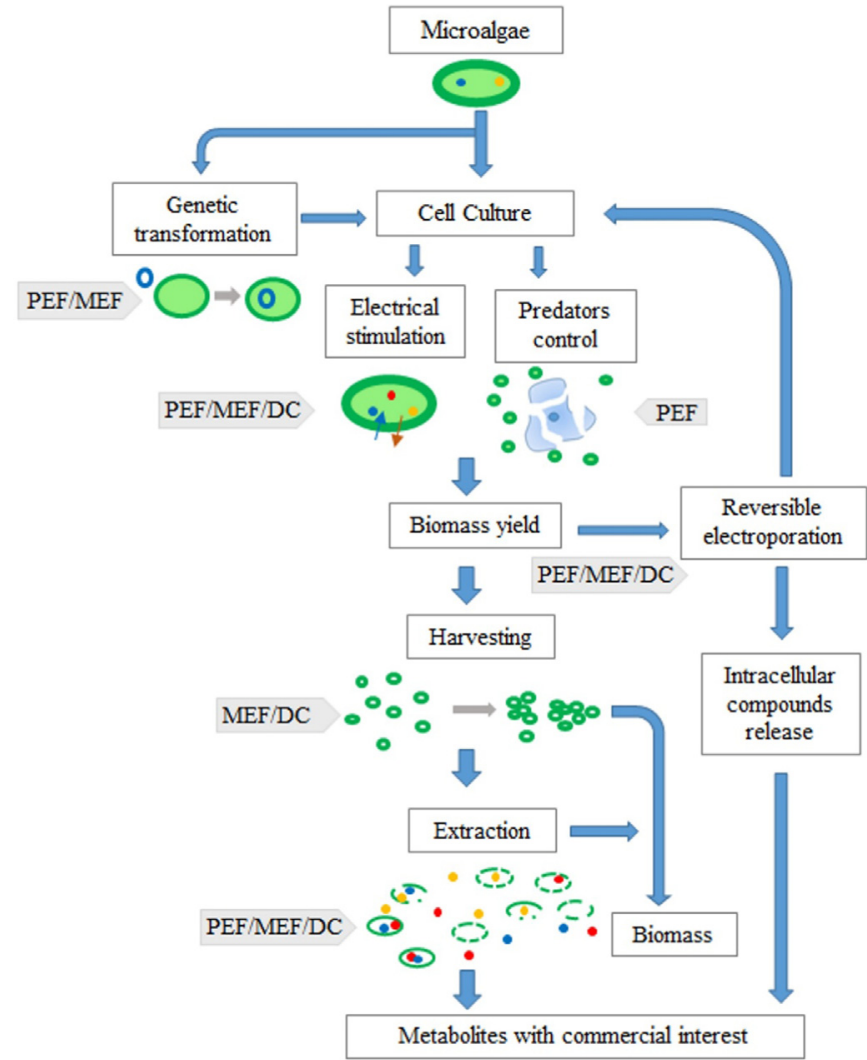

Fig. 5. General process diagram of microalgal biotechnology and the application of electrotechnologies in different stages of the process.

compounds and as micro-bioreactors has motivated new strategies for the intensification of their growth and metabolites production. When compared with other microbiological production systems, microalgae have several advantages. Commonly, their biomass doubles within $24 \mathrm{~h}$ and can be grown either phototrophically or heterotrophically, making them interesting for the production of therapeutic and industrially relevant products [80]. The genetic manipulation of microalgal species has revealed potential to improve several aspects of their cultivation and added-value compounds production, such as manipulation of the central carbon metabolism, antenna complex reduction or recombinant protein expression [80-82]. A particular focus has been given to the production of recombinant proteins of some microalgae species since they can be expressed from nuclear, mitochondrial and chloroplast genomes [80]. In reason of these features, microalgae are considered to be attractive systems for the development of recombinant proteins and production of bioactive compounds [83,84].

Electroporation emerged a few decades ago as an efficient technique for transformation of many organisms [85]. By using reversible electroporation, an efficient molecular transport across the plasma membrane can be achieved [86]. This process is almost exclusively carried out by low intensity PEF treatments. However, AC fields have also demonstrated their potential to electroporate cells aiming at genetic manipulation [87]. The efficiency of electroporation is dependent on different parameters, such as the field strength applied, temperature, pulse length, cell membrane features, and the concentration of genetic material [88]. The medium composition where electroporation is carried out can influence the process, namely cell survival, due to its interaction with the intracellular environment of permeabilized microorganisms during/after electrical treatment. Additionally, the intrinsic resistance and osmolarity of the medium, which affect pulse duration, as well as the amount of divalent ions, may also compromise the structural compounds of cells, thus affecting their normal behavior [89].
Efficient electroporation-mediated transformation was achieved in diverse cells of microalgae, such as naked cells, protoplasts, cell-wallreduced mutants, and other thin-walled cells $[80,89,90]$. For instance, the transformation of Chlorella species [88,91-95], D. salina [88,96-99], N. oculata $[100,101]$, D. viridis [102], and D. tertiolecta [103] by electroporation was already successfully performed.

\subsubsection{Control of culture's contaminants}

Biological contamination of microalgae cultures with predators or competing organisms can highly harm productivity, leading, in extreme cases, to the total loss of the culture. Thus, it is of key importance to develop effective tools for the selective elimination of these contaminants [104]. The application of PEF as a cell permeabilization and disruption method can be used effectively for selective cell elimination (i.e. predator control) - Table 1. The field strength can be a selective tool to process cells with different sizes, varying the efficiency with cell radius. Smaller cells need higher field strength to produce similar effects to those obtained on larger ones [105].

The application of an EF for $6 \mathrm{~h}$ on a contaminated microalgae culture showed selective effect on different organisms according to their membrane properties and sizes. As result, damage was inflicted to rotifers (predators) while no visible changes were induced on microalgae population [106]. PEF treatments may cause persisting effects on rotifers or other large predators leading to the decrease of their population on the following days after treatment [105]. Besides the larger size of rotifers, the absence of cell wall, as the case of amoeba, might also contribute for the selective destruction of predators when compared to microalgae. With respect to this, predators control usually requires a very low energy PEF treatment $(<1 \mathrm{kV} / \mathrm{cm}$ field strength), while commercially microalgae strains are normally affected by field strengths ranging between 4 and $40 \mathrm{kV} / \mathrm{cm}[106,107]$.

The field strength, the treated volume necessary per hour and the treatment time needed to cause predators death are the only parameters required to PEF application, which makes this technique a very interesting methodology, proven both in practice and at large scale $[105,106]$. In fact, this is already the target of a patent protection [108]. However, some contaminants (like microbes) are not affected by nonlethal field strengths for microalgae and thus, further developments are needed in this area.

\subsubsection{Enhanced mass transfer - improving growth kinetics}

Biostimulation of microbial cultures in order to potentiate growth and metabolic pathways has caught researchers' attention and produces significant results. The utilization of EF has also been demonstrated effective on improving microorganisms' growth and productivity [109]. Sublethal range EF shows effects on metabolic activity and cell membrane permeability of several organisms [73]. Among these effects are the lag phase reduction in $S$. cerevisiae by MEF and low intensity PEF $[110,111]$. Mattar et al. [111] also reported the increase of fermentation kinetics, suggesting an impact of EF in the cellular machinery (i.e. synthesis of RNA and enzymes, frequency of cell division events, among others) and an enhancement of mass transfer through the cellular membrane.

Despite the electrostimulation benefits reported in several organisms, its application on microalgae cultures still falls short. The response of Volvox algae to electric stimuli has been demonstrated, resulting to the polarization of their displacement in culture [112]. In $C$. vulgaris cultures, a $51 \%$ boost in the growth was achieved through the application of a $2.7 \mathrm{kV} / \mathrm{cm}$ static EF [113]. Using PEF of $40 \mathrm{kV} / \mathrm{cm}$ and 25 ns of duration, it was also possible to increase $C$. vulgaris biomass yield by $10-20 \%$ [114].

Mass transfer enhancement may also assist culture control and quantification of compounds of interest. Su et al. [115] have used the potential for mass transfer enhancement across the membrane by MEF to improve the labeling of microalgae intracellular lipids. This technique allowed reducing the decay and fluctuation of fluorescence 
intensity in C. vulgaris cells and enabled the rapid labeling of Spirulina sp. cells, increasing fluorescence intensity by $270 \%$.

\subsection{Downstream processing - harvesting}

The harvesting of microalgae is still a challenge to the commercialization of microalgal compounds due to their small size and poor colloidal stability in culture [116]. Some harvesting methods such as centrifugation, sedimentation, filtration, flotation and flocculation, or a combination of some of these, were already extensively studied for microalgae $[77,78,116-120]$.

The selection of the most appropriate harvesting technique isn't only dependent of the microalgae species but also of the nature and the value of the desired products. As an example, the harvesting of small size microalgae or with small density frequently requires longer processing times, particularly when using gravitational techniques [78].

In conventional coagulation/flocculation processes, $\mathrm{pH}$ changes and the addition of polymers or polyvalent metal ions such as iron $\left(\mathrm{Fe}^{3+}\right)$ or aluminum $\left(\mathrm{Al}^{3+}\right)$, cause charge neutralization and/or network formation. The new approach of electrochemical harvesting (ECH) techniques, based on the principle of electrocoagulation, electroflocculation and electroflotation, represents an innovative, effective, and cheap method for harvesting of microalgae, reducing significantly the addition of chemicals [116].

In electrocoagulation (EC), metal ions are generated due to oxidizing metal electrodes, causing the destabilization of colloid suspension and the coagulation of biomass [117]. During EC, the oxidation of the anode occurs under DC or low frequency AC field, which causes electrode depletion and, consequently, requires periodic electrode replacement [78]. Once the sacrificial electrode is consumed, an inexpensive material is recommended. This depletion results in metallic contamination of the harvested microalgae, representing the principal disadvantage of the EC process in terms of cost-efficiency. Dewatering methods that do not generate trace metals are preferred since the products obtained don't suffer any market value depreciation [77].

These electrolytic techniques of coagulation/flocculation have demonstrated great potential and high efficiencies. Efficient microalgae recoveries between $85 \%$ and $95 \%$ were obtained within $1 \mathrm{~h}$ using electrolytic flocculation with a power supply of approximately $5 \mathrm{~V}$ [117]. Similarly, Zenouzi et al. [120] observed a 97.4\% removal efficiency of $D$. salina after 3 min using electrolytic flocculation.

Electroflotation is also an electrolytic technique where bubbles resulting from the electrolysis of the water attach to the particulates in suspension and lift them up to the surface of the vessel [117]. Usually, in this technique the cathode is made from an inert material that is electrochemically non-degradable, thus reducing the electrode replacement costs and contamination issues.

The combination of electrocoagulation-flotation (ECF) arises as a promising alternative to conventional microalgae harvesting due to the simplicity and capability of process scale up. In the ECF process, coagulating ions are generated from the sacrificial electrode that are able to destabilize microalgae suspension. Additionally, the destabilized microalgae cells aggregate and form flocs, that are captured by the microbubbles $\left(\mathrm{H}_{2}\right.$ and $\left.\mathrm{O}_{2}\right)$ produced by the electrodes [118]. The use of ECF for removal of microalgae from drinking or wastewater was investigated in a few studies [118,121-124] but its application as a method of collecting microalgae biomass still requires additional studies.

On an innovative methodology, Kim et al. [125] pointed the combination of EC and electroflotation as a continuous cultivation and electrolytic microalgae harvesting method. In this method, one electrode is made of a consumable material and the other is made of a stable material. By inverting the DC field and changing the polarity of the electrodes, three operating modes were tested - continuous electrolytic microalgae harvesting with polarity exchange, electroflotation, and ECF - being the first the most efficient one.
The successful application of ECF for water treatment depends on process parameters (i.e. electrode material, current density and temperature) and medium properties such as $\mathrm{pH}$ and existing ions; for example, several pollutant materials (oil, heavy metals, among others) can be removed due to the beneficial action of chloride ions [118]. Its importance was also demonstrated in microalgae harvesting because of the generation of active chlorine, which decreases zeta potential and enhances the release of metal ions. Thus, for practical applications, the presence of $\mathrm{Cl}^{-}$in natural water bodies should not be overlooked.

The utilization of ECF has also shown to be more effective if a sedimentation period between ECF process and the microalgae flocs removal is included, once microalgae suspension continues unstable after its removal. This destabilization could be faster with greater current densities; however, it will also lead to higher release of metal ions from the sacrificial anode and higher power consumption. The increasing of turbulence and reduction of initial $\mathrm{pH}$ could increase the efficiency of ECF as well when aluminum is used as anode [119].

Another interesting method for harvesting of microalgae with no need for the addition of chemicals is the electrophoresis. In this method, an $\mathrm{EF}$ is applied and the dispersed particles move relative to a fluid. Once the microalgae have a net negative charge and their water-based growth media are rich in monovalent sodium $\left(\mathrm{Na}^{+}\right)$and potassium $\left(\mathrm{K}^{+}\right)$ions, cells could move towards the anode when subjected to a DC EF [77]. This would result on cell concentration as the negatively charged algae cells move towards the anode where they lose charge causing agglomeration and the formation of flocs [126]. In this process, the use of a non-sacrificial electrode would alleviate the issue of metal ions contamination.

Dielectrophoresis (DEP) can also be an important application both in fractionation and characterization of several different cell groups and harvesting total cell content. A mixture of two or more microalgae populations can be fractionated by dielectrophoresis in case of presenting different dielectric permitivities, electric conductivities or geometries [127]. Moreover, the separation is more successful if such populations differ in their crossover frequency and if the field frequency applied is chosen in order to have one population being subject to the negative DEP and the other one to the positive DEP. This way, the dielectrophorectic force operates in opposite directions in the different microalgae populations [128]. Several examples of DEP applications are found on the literature. Using fresh water algae Chlamydomonas reinhardtii, the efficiency of AC-field to agglomerate and capture cells without appreciable cell damage was demonstrated [68]. They also demonstrate the influence of operational parameters such as field intensity, frequency, and salt composition of the medium on the process. Song et al. [129] described a microfluidic-DEP method to continuously separate marine algae and polystyrene particles of similar sizes. The separation of $C$. vulgaris cells with different lipid content has also been demonstrated [130]. The selective separation is the result of positive or negative-DEP, responsive to the lipid content of each cell, conductivity of the medium, and the electrical parameters applied. The same principles were used to develop a continuous micro device that allowed achieving high efficiencies on the separation of Chlamydomonas reinhardtii based on its lipid content [131]. Despite the efficiency and potential presented by these techniques, the relatively high cost of the microfluidic devices and the low processing capacity, relegate DEP to screening and analytic applications. However, with the advances in microfabrication and subsequent costs reduction, it may be possible to produce a microfluidics-based device in a near future capable of reaching a cost-effective fractioning and separation of microalgae.

\subsection{Downstream processing - electropermeabilization and extraction}

Undoubtedly the most consensual and reviewed effect of EF processing is permeabilization of cellular material, making of EF treatments a promising alternative to conventional cell permeabilization methods (Table 1). The exposure of cells to an external EF can alter the 
structure of their membrane since it causes a transmembrane charge exchange. Consequently, membrane loses its barrier function and becomes permeable, a phenomenon often referred to as electroporation or electropermeabilization $[67,132]$. These effects are inherent to all $\mathrm{EF}$ applications since the threshold of transmembrane potential $(\sim 0.2-1 \mathrm{~V})$ is overcome. However, the restrictions in the applied field strength in the case of non-pulsed EF techniques limit their electroporation effects. Thus, PEF arises as the predominant EF-related technique to assist or promote extraction of intracellular compounds. The possibility of utilizing $\mathrm{EF}$ with several dozens of $\mathrm{kV}$ allows effective cellular permeabilization and rupture even in small unicellular organisms. Nonetheless, new approaches using other electrotechniques are showing interesting perspectives in permeation of microalgae cells and extraction of their intracellular metabolites.

\subsubsection{High energy pulses}

PEF used for extraction of compounds in microalgal processing was the focus of a large variety of works, either in research or in pilot/ industrial applications [133-136]. It has also demonstrated a high potential for increasing the extraction of valuable components from microalgae [137]. Recalling a previous section, the key electrical parameters that influence the PEF-induced permeabilization efficiency are field strength, number of pulses applied, pulse duration and shape, and specific treatment energy. According to the parameters applied, the reversibility of membrane permeabilization can be influenced. An irreversible cell membrane permeabilization leads to an effective extraction by rupture of membrane and intracellular structures, making easier the solvent access into the cell and thus the release of valuable compounds [132,138]. The bulk temperature during the treatment may result in the degradation of labile compounds including the ones inside the cells $[139,140]$, but also contribute to an increased extraction of lipids [140-142] and proteins [143]. However, in the case of proteins, the nutritional and functional properties (e.g. digestibility) may be affected [144]. PEF enables the extraction of valuable compounds with low undesirable changes in the target material and without introducing impurities into the process. This is a gentle and scalable cell disruption process that can be performed either in batch or continuous mode [139].

Microalgae are a promising feedstock for high value lipid compounds and continuous extraction of these compounds can be amplified by applying green solvents, at short contact times, together with PEF processing [142]. Particularly, the wet extraction from PEF-treated algal biomass seems to be economically promising for lipid processing. While the dry-based processing requires at least $7 \mathrm{MJ} / \mathrm{kg} \mathrm{dw}$, the wet extraction using PEF treatment requires only $1.5 \mathrm{MJ} / \mathrm{kg} \mathrm{dw}$ [141].

$\mathrm{PEF}$ technology is recognized as a "green" method for the extraction of valuable compounds from microalgae, preventing the use of chemical additives $[137,143]$. Studies with $C$. vulgaris and $H$. pluvialis, grown in freshwater environments under different conditions, revealed significant extraction of cytoplasmatic proteins when applying PEF. The cell wall alterations induced by PEF treatment, commonly caused by a single passage through the pulsation chamber, increase its porosity and, consequently, the release of cytoplasmic proteins. These electro-extractions showed more consistent results at $24 \mathrm{~h}$ post-treatment [145]. To induce the permeabilization of smaller organelles, a larger field strength is required, since it is subject to a screening effect of citoplasmatic membrane and depends of the PEF parameters [146].

The possibility of enhancement the recovery yield of pigments (chlorophylls a and b and carotenoids) from microalgae by PEF was recently reported [137]. To extract these pigments, the cytoplasmatic and chloroplast membrane need to be permeabilized since they are located in the chloroplasts. Just $1 \mathrm{~h}$ after treatment, both membranes were permeabilized and the photosynthetic pigments were extracted. The application of an EF of $20 \mathrm{kV} / \mathrm{cm}$ during $75 \mu$ s increased the extraction of chlorophylls a and $\mathrm{b}$, as well as carotenoids, from $C$. vulgaris just after the PEF treatment in 1.2, 1.6, and 2.1 times, respectively.
Remarkable levels of pigments extracted from PEF-pretreated microalgae were observed when binary solvent mixtures (water and organic solvent) were used [137]. Besides the influence of PEF parameters (such as EF strength and treatment time), the extraction efficiency also depends on the elapsed time between the application of the treatment and the extraction process.

HVED techniques have also proven the potential to achieve inactivation of microalgae [147-149]. In the particular case of extraction, it has proven to enhance the process in several biological materials $[63,150,151]$. HVED showed to be particularly effective in the extraction of soluble ionic compounds from Nannochloropsis sp. [152]. Its potential to increase the recovery of pigments from microalgae was also reported by Barba et al. [153]. Despite the relatively limited application of this technology in microalgae field, it may provide a powerful option for mechanical disintegration of the cell walls and thus the recovery of biomacromolecules of high molecular weight, as the case of proteins. On the other hand, the consequences of the process itself (production of localized high EFs, shockwaves, cavitation, turbulences, radicals, high energy radiation, among others) can cause excessive cellular damage, extraction of undesired intracellular compounds, and degradation of the desired ones.

\subsubsection{Moderate electric fields}

Regardless of the predominance of literature reports and pilot/industrial applications of PEF, non-pulsed EF techniques involving AC or DC electrical treatments have also demonstrated their potential to promote and assist extraction (Table 1). A DC electrochemical method to extract intracellular compounds was evaluated for the simultaneous extraction of lipids and proteins from C. vulgaris [154], revealing high extraction yields in both cases. During electro-harvesting processes, the release of intracellular metabolites has also been reported through the use of AC electroflotation with resistant electrodes [155], demonstrating high recovery (95-99\%) of microalgae from a wastewater treatment plant with simultaneous cell disruption and resulting in the release of their lipid content. In a subsequent study [156], this process was compared with microwaving as rupture alternative, revealing AC electroflotation as a more attractive technique in terms of cost-effectiveness. DC has also been used successfully as a strategy to improve diatomite quality. The EF application removed impurities from the cell clogged pores resulting in an improved porosity, specific surface area, and enhanced absorptive efficiency of diatomite [157].

The electroporation effects of MEF and their use in extraction of compounds of interest from cells is well recognized. Either alone or conjugated with thermal effects, the potential for MEF extraction has been significantly reviewed, especially in vegetable tissues $[67,72,158-160]$. Additionally, in unicellular organisms such as $S$. cerevisiae, the leakage of intracellular material has not only been shown to be enhanced by ohmic heating but also to be positively responsive to the increase of EF strength and frequency. These reports demonstrated the effectiveness of MEF in performing or assisting extraction processes in different cellular matrices. However, MEF application in microalgae is considered to be impaired by their generally smaller size and high resistance, demanding higher intensity treatment as PEF or HVED. Nonetheless, there are some successful cases of performed (or at least assisted) extraction by MEF in microalgae (Table 1). Silva et al. [161] tested several pretreatment methods for lipid extraction in mixed microalgae suspensions (i.e. ultrasonication, microwaving, autoclave and electroflotation by $\mathrm{AC}$ ), revealing that the application of AC field was the best option considering the cost/efficiency ratio. The effect of MEF was also evaluated on the pretreatment and extraction of lipids and carotenoids from Heterochlorella luteoviridis in a water and ethanol mixture [162]. Results have shown that MEF positively affects specifically the carotenoid extraction, while lipid is only influenced by the solvent. The extraction of pigments from $C$. vulgaris has also been demonstrated by our research group through the application of ohmic heating [163]. Electrokinetics, conjugated with microfluidics, has been 
previously addressed in this review. Yet, in another innovative approach, Bahi et al. [164] developed an integrated microfluidics system for concentration and subsequent lysis of marine algae Karenia brevis. With the objective of extracting and purifying RNA, cells were concentrated by DEP using $1 \mathrm{~V}$ and $20 \mathrm{kHz}$ for $10 \mathrm{~s}$ and changing to $60 \mathrm{~V}$ and $600 \mathrm{kHz}$ up to $15 \mathrm{~s}$ to promote lysis. The process achieved great efficiency and resulted in RNA with very little damage. It is clear that an $\mathrm{EF}$ of this magnitude can easily achieve strengths of $1 \times 10^{4}-1 \times 10^{5}$ $\mathrm{V} / \mathrm{cm}$ when applied at microscale. This range is equal to or higher than typical PEF applications with a power supply meeting MEF specifications, allowing greater operational flexibility and exploiting the advantages of both systems.

\section{Future trends and perspectives}

Electrotechnologies are establishing a foothold in microalgae biorefinery. These techniques, with all their singularities, offer the potential to improve cell disruption and extraction steps in downstream processing, avoiding the use of auxiliary reagents such as solvents and other chemicals. The cost of these novel equipments has declined greatly over the past years, mostly due to the increasing number of manufacturers and technological developments (e.g. less expensive power supplies and a wide variety of equipment designs), thus allowing to predict that these technologies will be economically competitive in a near future. However, in order to become economically feasible these technologies should also be designed and rethought in an integrative way together with simplified downstream processes, in which cell disruption, extraction and fractionation are optimized in a single step [166]. Another challenge to be overcome is related with a more fundamental knowledge about the effects of a multiplicity of electrical variables (e.g. waveform, number of pulses, EF intensity, electrical frequency, electrical current, current density, Joule heating) on the complexity of microalgae cells features (i.e. cell size, cell wall structure and thickness, and electrical conductivity of the culture medium). PEF, as a low-shear mechanical stress (when compared with bead milling) and low-temperature cell disruption technique, is in the frontline of innovative nonthermal recovery of thermos-labile molecules. However, it is still inefficient for microalgae presenting stronger cell wall structures, thus requiring additional pretreatments to soften the cells prior to PEF application. MEF presents potential to combine electrical effects with high temperatures (Joule heating), offering the possibility of a synergistic effect on the disruption of cell walls and subsequent compounds extraction. The elevated temperatures applied may however cause degradation of the compounds of interest. Eventually, a promising approach will be to combine electrical treatments performed at mild temperature conditions. A proper control of electroheating treatments may allow tailoring extraction or even fractionation of valuable components. Though, a better understanding about the interaction of EFs with the physiology of microalgae cell wall is still necessary. The effects of long time exposure of microalgae cells to low/moderate EFs during harvesting need to be investigated; these electrical protocols can trigger biological stress responses on microalgae cells turning them more viable and productive, or even allowing a greater weakening of the cell wall at a final stage of the application. Unlike emerging technologies such as PEF, MEF and ECF, which rely on substantial fundamental studies, more recent approaches using electro stimulation, or the conjugation of microfluidic electrotechnologies, still have a long way to complete implementation. However, they hold an enormous potential and should not be overlooked, being expected a rapid development in a near future.

Another aspect that should be highlighted is that electrotechnologies have an eco-friendly status, being considered locally clean processes that use electrical energy (that can be obtained through a renewable source such as hydroelectric power), promote increased energetic efficiency, and reduce water disposal, gas and effluent emissions. These technological features can be crucial to improve sustainability and environmental performance towards a biologically based economy, which is a current issue on the political agenda and public awareness. However, in order to ensure the economic viability of these technologies, detailed results from industrial tests are critical. Case studies with industrial relevance should focus on the role of electrotechniques in the access to different valuable co-products from cultivated microalgae (such as proteins, lipids, carbohydrates and pigments), envisioning yield, selectivity, simple instrumentation and reduced energy costs [79]. Only technologies that would be able to follow these assumptions on a larger scale will effectively contribute to reducing the total costs of implementing a microalgae biorefinery factory.

\section{Conclusions}

Electrotechnologies encompass important environmental and processing advantages related with high energetic efficiencies and a less intensive use of non-renewable energy and natural resources.

In reason of the reasonable critical mass and existence of fundamental knowledge, which has been increasing over the last few years, these techniques offer the potential to be applied in upstream and downstream operations of microalgae exploitation - e.g. genetic transformation and extraction of valuable compounds. It is possible to breakdown microalgae cellular matrices (i.e. electroporation effect) and promote the release of important bioactive molecules through the use of high voltage pulses protocols. These techniques can also offer the opportunity to combine electrical and thermal effects (i.e. electroheating), showing potential to inactivate culture contaminants. Besides the great adaptability and versatility - offering different processing approaches (thermal, non-thermal or a combination of both) - the number manufacturers of PEF and MEF equipment at laboratory and industrial scale with different designs is also increasing, thus providing the necessary conditions for application on a larger scale.

However, the effective role and potential benefits of these technologies will only be unveiled once some bottlenecks at the level of fundamental and applied knowledge have been overcome, such as the need for: i) a better understanding of how electricity-based treatments can be tailored to promote a desired effect (e.g. cell disruption) on different microalgae strains; ii) carrying out demonstrative projects at industrial scale aiming high levels of technology readiness that should include detailed economic analyses and life cycle assessment; and iii) aligning electrotechnologies implementation with a large scale biorefinery concept through an integrated and simplified strategy of production and valorisation of all bulk constituents.

Techniques based on the application of EFs are very promising for niche downstream/upstream applications, replacing or at least complementing well-established techniques. However, a successful industrial implementation of these techniques will depend on a critical question - how much can they reduce total production costs? Additionally, these technologies might have a significant role in overcoming some of the bottlenecks of the process, thus increasing costeffectiveness of a given microalgae biomass exploitation targeting the whole production process by, for example, enabling the implementation of a biorefinery approach.

\section{Acknowledgments}

This research work was supported by the Grants SFRH/BPD/98694/ 2013 (Bruno Fernandes), SFRH/BD/110723/2015 (Rui Rodrigues), SFRH/BPD/81887/2011 (Ricardo Pereira) and SFRH/BD/52335/2013 (Pedro Geada) from Fundação para a Ciência e a Tecnologia (Portugal). Luís Loureiro is recipient of a fellowship supported by a doctoral advanced training (call NORTE-69-2015-15) funded by the European Social Fund under the scope of Norte2020 - Programa Operacional Regional do Norte. This study was also supported by the Portuguese Foundation for Science and Technology (FCT) under the scope of the strategic funding of UID/BIO/04469/2013 unit and COMPETE 2020 
(POCI-01-FEDER-006684), Project UID/Multi/04423/2013, Project RECI/BBB-EBI/0179/2012 (FCOMP-01-0124-FEDER-027462), FCT Strategic Project of UID/BIO/04469/2013 unit, by the project NOVELMAR (reference NORTE-01-0145-FEDER-000035), co-financed by the North Portugal Regional Operational Programme (Norte 2020) under the National Strategic Reference Framework (NSRF), through the ERDF and by BioTecNorte operation (NORTE-01-0145-FEDER 000004) funded by the European Regional Development Fund under the scope of Norte2020 - Programa Operacional Regional do Norte.

\section{References}

[1] Falkowski PG, Raven JA. Aquatic photosynthesis. Oxford: Blackwell Science; 1997.

[2] Bahadar A, Khan MB. Progress in energy from microalgae: a review. Renew Sustain Energy Rev 2013;27:128-48.

[3] Lee RE. Phycology. New York: Cambridge University Press; 1980.

[4] Priyadarshani I, Rath B. Commercial and industrial applications of microalgae - a review. J Algal Biomass- Utln 2012;3:89-100.

[5] Dragone G, Fernandes B, Vicente AA, Teixeira JA. Third generation biofuels from microalgae. In: Méndez-Vilas A, editor. Current research, technology and education topics in applied microbiology and microbial biotechnology. Badajoz: Formatex; 2010. p. 1355-66.

[6] Klinthong W, Yang Y-H, Huang C-H, Tan C-S. A review: microalgae and their applications in $\mathrm{CO}_{2}$ capture and renewable energy. Aerosol Air Qual Res 2015;15:712-42.

[7] Geada P, Vasconcelos V, Vicente A, Fernandes B. Chapter 13: microalgal biomass cultivation. In: Rastogi R, Madamwar D, Pandey A, editors. Algal green chemistry: recent progress in biotechnology. Amsterdam: Elsevier; 2017. p. 257-84.

[8] Norton TA, Melkonian M, Andersen RA. Algal biodiversity. Phycologia 1996;35:308-26.

[9] Pulz O, Gross W. Valuable products from biotechnology of microalgae. App Microbiol Biotechnol 2004:65:635-48.

[10] Senhorinho GNA, Ross GM, Scott JA. Cyanobacteria and eukaryotic microalgae as potential sources of antibiotics. Phycologia 2015;54:271-82

[11] Spolaore P, Joannis-Cassan C, Duran E, Isambert A. Commercial applications of microalgae. J Biosci Bioeng 2006;101:87-96.

[12] Fernandes BD, Mota A, Teixeira JA, Vicente AA. Continuous cultivation of photosynthetic microorganisms: approaches, applications and future trends. Biotechnol Adv 2015;33:1228-45.

[13] Fernandes BD, Mota A, Ferreira A, Dragone G, Teixeira JA, Vicente AA. Characterization of split cylinder airlift photobioreactors for efficient microalgae cultivation. Chem Eng Sci 2014;117:445-54.

[14] Fernandes BD, Dragone GM, Teixeira JA, Vicente AA. Light regime characterization in an airlift photobioreactor for production of microalgae with high starch content. Appl Biochem Biotechnol 2010;161:218-26.

[15] Um B-H, Kim Y-S. Review: a chance for Korea to advance algal-biodiesel technology. Ind Eng Chem Res 2009;15:1-7.

[16] Chen J, Wang Y, Benemann JR, Zhang X, Hu H, Qin S. Microalgal industry in China: challenges and prospects. J Appl Phycol 2016;28:715-25.

[17] Hong JW, Jo S-W, Yoon H-S. Research and development for algae-based tech nologies in Korea: a review of algae biofuel production. Photosynth Res 2015;123:297-303.

[18] Becker W. Microalgae in human and animal nutrition. In: Richmond A, editor. Handbook of microalgal culture: biotechnology and applied phycology. Oxford: Blackwell Publishing Ltd; 2004. p. 312-51.

[19] Pagnussatt FA, Spier F, Bertolin TE, Costa JAV, Gutkoski LC. Technological and nutritional assessment of dry pasta with oatmeal and the microalga Spirulina platensis. Braz J Food Technol 2014;17:296-304.

[20] Campo JAD, García-González M, Guerrero MG. Outdoor cultivation of microalgae for carotenoid production: current state and perspectives. Appl Microbiol Biotechnol 2007;74:1163-74.

[21] Canela APRF, Rosa PTV, Marques MOM, Meireles MAA. Supercritical fluid extraction of fatty acids and carotenoids from the microalgae Spirulina maxima. Ind Eng Chem Res 2002;41:3012-8.

[22] Brennan L, Owende P. Biofuels from microalgae - a review of technologies for production, processing, and extractions of biofuels and co-products. Renew Sust Energ Rev 2010;14:557-77.

[23] Mata TM, Martins AA, Caetano NS. Microalgae for biodiesel production and other applications: a review. Renew Sustain Energy Rev 2010;14:217-32.

[24] Anjos M, Fernandes BD, Vicente AA, Teixeira JA, Dragone G. Optimization of $\mathrm{CO}_{2}$ bio-mitigation by Chlorella vulgaris. Bioresour Technol 2013;139:149-54.

[25] Fernandes B, Teixeira J, Dragone G, Vicente AA, Kawano S, Bišová K, et al. Relationship between starch and lipid accumulation induced by nutrient depletion and replenishment in the microalga Parachlorella kessleri. Bioresour Technol 2013;144:268-74.

[26] Razzak SA, Hossain MM, Lucky RA, Bassi AS, Lasa $\mathrm{H}$. Integrated $\mathrm{CO}_{2}$ capture, wastewater treatment and biofuel production by microalgae culturing - a review. Renew Sustain Energy Rev 2013;27:622-53.

[27] Almeida JR, Freitas M, Cruz S, Leão PN, Vasconcelos V, Cunha I. Acetylcholinesterase in biofouling species: characterization and mode of action of cyanobacteria-derived antifouling agents. Toxins 2015;7:2739-56.

[28] Costa M, Garcia M, Costa-Rodrigues J, Costa MS, Ribeiro MJ, Fernandes MH, et al.
Exploring bioactive properties of marine cyanobacteria isolated from the Portuguese coast: high potential as a source of anticancer compounds. Mar Drugs 2014;12:98-114.

[29] Stolz P, Obermayer B. Manufacturing microalgae for skin care. Cosmet Toile 2005;120:99-106.

[30] Edge R, McGarvey DJ, Truscott TG. The carotenoids as anti-oxidants - a review. J Photochem Photobiol B 1997;41:189-200.

[31] García-González M, Moreno J, Manzano JC, Florencio FJ, Guerrero MG. Production of Dunaliella salina biomass rich in 9-cis- $\beta$-carotene and lutein in a closed tubular photobioreactor. J Biotechnol 2005;115:81-90.

[32] Lorenz RT, Cysewski GR. Commercial potential for Haematococcus microalgae as a natural source of astaxanthin. Trends Biotechnol 2000;18:160-7.

[33] Barreiro A, Vasconcelos V. Interactions between allelopathic properties and growth kinetics in four freshwater phytoplankton species studied by model simulations. Aquat Ecol 2014;48:191-205.

[34] Geada P, Gkelis S, Teixeira J, Vasconcelos V, Vicente AA, Fernandes B. Chapter 17: cyanobacterial toxins as a high value added product. In: Muñoz R, GonzalezFernandez C, editors. Microalgae-based biofuels and bioproducts. Cambridge: Woodhead Publishing; 2017. p. 405-32.

[35] Leão PN, Costa M, Ramos V, Pereira AR, Fernandes VC, Domingues VF, et al. Antitumor activity of hierridin B, a cyanobacterial secondary metabolite found in both filamentous and unicellular marine strains. PLoS One 2013;8:e69562.

[36] Martins J, Leão PN, Ramos V, Vasconcelos V. N-terminal protease gene phylogeny reveals the potential for novel cyanobactin diversity in cyanobacteria. Mar Drugs 2013;11:4902-16

[37] Schenk PM, Thomas-Hall SR, Stephens E, Marx UC, Mussgnug JH, Posten C, et al Second generation biofuels: high-efficiency microalgae for biodiesel production. Bioenerg Res 2008;1:20-43.

[38] Vanthoor-Koopmans M, Wijffels RH, Barbosa MJ, Eppink MHM. Biorefinery of microalgae for food and fuel. Bioresour Technol 2013;135:142-9.

[39] Wang B, Li Y, Wu N, Lan CQ. $\mathrm{CO}_{2}$ bio-mitigation using microalgae. Appl Microbio Biotechnol 2008;79:707-18.

[40] Norsker N-H, Barbosa MJ, Vermuë MH, Wijffels RH. Microalgal production - a close look at the economics. Biotechnol Adv 2011;29:24-7.

[41] Wijffels RH, Barbosa MJ, Eppink MHM. Microalgae for the production of bulk chemicals and biofuels. Biofuels Bioprod Bioref 2010;4:287-95.

[42] Sakr M, Liu S. A comprehensive review on applications of ohmic heating (OH). Renew Sustain Energy Rev 2014;39:262-9.

[43] Galanakis CM. Emerging technologies for the production of nutraceuticals from agricultural by-products: a viewpoint of opportunities and challenges. Food Bioprod Process 2013;91:575-9.

[44] Rocha CMR, Genisheva Z, Ferreira-Santos P, Rodrigues R, Vicente AA, Teixeira JA, et al. Electric field-based technologies for valorization of bioresources. Bioresour Technol 2018;254:325-39.

[45] Puértolas E, Barba FJ. Electrotechnologies applied to valorization of by-products from food industry: main findings, energy and economic cost of their in dustrialization. Food Bioprod Process 2016;100:172-84.

[46] Sastry S. Ohmic heating and moderate electric field processing. Food Sci Technol Int 2008;14:419-22.

[47] Velizarov S. Electric and magnetic fields in microbial biotechnology: possibilities, limitations, and perspectives. Electromagn Biol Med 1999;18:185-212.

[48] Tsong TY. Electroporation of cell membranes. Biophys J 1991;60:297-306.

[49] Lebovka NI, Kupchik MP, Sereda K, Vorobiev E. Electrostimulated thermal permeabilisation of potato tissues. Biosyst Eng 2008;99:76-80.

[50] Wong PK, Chen C-Y, Wang T-H, Ho C-M. Electrokinetic bioprocessor for concentrating cells and molecules. Anal Chem 2004;76:6908-14.

[51] Vorobiev E, Lebovka N. Extraction from foods and biomaterials enhanced by pulsed electric energy. In: Knoerzer K, Juliano P, Smithers GW, editors. Innovative food processing technologies: extraction, separation, component modification and process intensification. Cambridge: Woodhead Publishing; 2016. p. 31-56.

[52] Mahnič-Kalamiza S, Vorobiev E, Miklavčič D. Electroporation in food processing and biorefinery. J Membr Biol 2014:247:1279-304.

[53] Pucihar G, Kotnik T, Miklavčič D. Measuring the induced membrane voltage with Di-8-ANEPPS. J Vis Exp 2009;33:e1659.

[54] Alvarez I, Pagán R, Condón S, Raso J. The influence of process parameters for the inactivation of Listeria monocytogenes by pulsed electric fields. Int J Food Microbiol 2003;87:87-95.

[55] Mohamed MEA, Eissa AHA. Chapter 11: pulsed electric fields for food processing technology. In: Eissa AA, editor. Structure and function of food engineering. London: InTech; 2012. p. 275-306.

[56] Ravishankar S, Zhang H, Kempkes ML. Pulsed electric fields. Food Sci Technol Int $2008 ; 14: 429-32$

[57] Zhang Q, Barbosa-Cánovas GV, Swanson BG. Engineering aspects of pulsed electric field pasteurization. J Food Eng 1995;25:261-81.

[58] Ersus S, Halil Oztop M, McCarthy MJ, Barrett DM. Disintegration efficiency of pulsed electric field induced effects on onion (Allium cepa L.) tissues as a function of pulse protocol and determination of cell integrity by ${ }^{1} \mathrm{H}-\mathrm{NMR}$ relaxometry. $\mathrm{J}$ Food Sci 2010;75:E444-52.

[59] Abram F, Smelt JPPM, Bos R, Wouters PC. Modelling and optimization of inactivation of Lactobacillus plantarum by pulsed electric field treatment. J App Microbiol 2003;94:571-9.

[60] Raso J, Alvarez I, Condón S, Trepat FJS. Predicting inactivation of Salmonella senftenberg by pulsed electric fields. Innov Food Sci Emerg Technol 2000;1:21-9.

[61] Vorobiev E, Lebovka N. Enhanced extraction from solid foods and biosuspensions by pulsed electrical energy. Food Eng Rev 2010;2:95-108.

[62] Boussetta N, Vorobiev E, Le LH, Cordin-Falcimaigne A, Lanoisellé J-L. Application 
of electrical treatments in alcoholic solvent for polyphenols extraction from grape seeds. Food Sci Technol 2012;46:127-34.

[63] Boussetta N, Vorobiev E. Extraction of valuable biocompounds assisted by high voltage electrical discharges: a review. C R Chim 2014;17:197-203.

[64] Gnapowski S, Ruma, Akiyama H, Sakugawa T. Algae treatment effects by pulse power discharge in the water. In: Plasma Science (ICOPS), Abstracts IEEE international conference on plasma science, Edinburgh, UK; 2012. DOI: 〈http://dx.doi. org/10.1109/PLASMA.2012.6383439>.

[65] Machado LF, Pereira RN, Martins RC, Teixeira JA, Vicente AA. Moderate electric fields can inactivate Escherichia coli at room temperature. J Food Eng 2010;96:520-7.

[66] Kirson ED, Gurvich Z, Schneiderman R, Dekel E, Itzhaki A, Wasserman Y, et al. Disruption of cancer cell replication by alternating electric fields. Cancer Res 2004;64:3288-95.

[67] Sensoy I, Sastry SK. Extraction using moderate electric fields. J Food Sci 2004;69:FEP7-13.

[68] Suscillon C, Velev OD, Slaveykova VI. Alternating current-dielectrophoresis driven on-chip collection and chaining of green microalgae in freshwaters. Biomicrofluidics 2013;7:24109.

[69] Shawki MM, Farid A. Low electric field parameters required to induce death of cancer cells. Electromagn Biol Med 2014;33:159-63.

[70] Pataro G, Barca GMJ, Pereira RN, Vicente AA, Teixeira JA, Ferrari G. Quantification of metal release from stainless steel electrodes during conventional and pulsed ohmic heating. Innov Food Sci Emerg Technol 2014;21:66-73.

[71] Schwan HP. Nonthermal cellular effects of electromagnetic fields: AC-field induced ponderomotoric forces. Br J Cancer Suppl 1982;5:220-4.

[72] Kulshrestha S, Sastry S. Frequency and voltage effects on enhanced diffusion during moderate electric field (MEF) treatment. Innov Food Sci Emerg Technol 2003;4:189-94.

[73] Loghavi L, Sastry SK, Youssef AE. Effect of moderate electric field frequency and growth stage on the cell membrane permeability of Lactobacillus acidophilus. Biotechnol Prog 2009;25:85-94.

[74] Yoon, Won S, Lee CYJ, Kim K-M, Lee C-H. Leakage of cellular materials from Saccharomyces cerevisiae by ohmic heating. J Microbiol Biotechnol 2002;12:183-8.

[75] Pereira RN, Vicente AA. Environmental impact of novel thermal and non-thermal technologies in food processing. Food Res Int 2010;43:1936-43.

[76] Hamann CH, Hamnett A, Vielstich W. Electrochemistry. 2nd ed. Weinheim: WileyVCH; 2007.

[77] Pearsall RV, Connely RL, Fountain ME, Hearn CS, Werst MD, Hebner RE, et al. Electrically dewatering microalgae. IEEE Trans Dielectr Electr Insul 2011;18:1578-83.

[78] Guldhe A, Misra R, Singh P, Rawat I, Bux F. An innovative electrochemical process to alleviate the challenges for harvesting of small size microalgae by using nonsacrificial carbon electrodes. Algal Res 2016;19:292-8.

[79] Poojary MM, Barba FJ, Aliakbarian B, Donsi F, Pataro G, Dias DA, et al. Innovative alternative technologies to extract carotenoids from microalgae and seaweeds. Mar Drugs 2016;14:214-47.

[80] Gong Y, Hu H, Gao Y, Xu X, Gao H. Microalgae as platforms for production of recombinant proteins and valuable compounds: progress and prospects. J Ind Microbiol Biotechnol 2011;38:1879-90.

[81] Radakovits R, Jinkerson RE, Darzins A, Posewitz MC. Genetic engineering of algae for enhanced biofuel production. Eukaryot Cell 2010;9:486-501.

[82] Simionato D, Basso S, Giacometti GM, Morosinotto T. Optimization of light use efficiency for biofuel production in algae. Biophys Chem 2013;182:71-8.

[83] Michalak I, Chojnacka K. Algae as production systems of bioactive compounds. Eng Life Sci 2015;15:160-76.

[84] Rosales-Mendoza S, Paz-Maldonado LMT, Soria-Guerra RE. Chlamydomonas reinhardtii as a viable platform for the production of recombinant proteins: current status and perspectives. Plant Cell Rep 2012;31:479-94.

[85] Coll JM. Review. Methodologies for transferring DNA into eukaryotic microalgae. Span J Agric Res 2006;4:316-30.

[86] Azencott HR, Peter GF, Prausnitz MR. Influence of the cell wall on intracellular delivery to algal cells by electroporation and sonication. Ultrasound Med Biol 2007;33:1805-17.

[87] Zhan Y, Cao Z, Bao N, Li J, Wang J, Geng T, et al. Low-frequency ac electroporation shows strong frequency dependence and yields comparable transfection results to dc electroporation. J Control Release 2012;160:570-6.

[88] Wang C, Wang Y, Su Q, Gao X. Transient expression of the GUS gene in a unicellular marine green alga, Chlorella sp. MACC/C95, via electroporation. Biotechnol Bioprocess Eng 2007;12:180-3.

[89] Toyomizu M, Suzuki K, Kawata Y, Kojima H, Akiba Y. Effective transformation of the cyanobacterium Spirulina platensis using electroporation. J Appl Phycol 2001;13:209-14.

[90] Potvin G, Zhang Z. Strategies for high-level recombinant protein expression in transgenic microalgae: a review. Biotechnol Adv 2010;28:910-8.

[91] Chow K-C, Tung WL. Electrotransformation of Chlorella vulgaris. Plant Cell Rep 1999;18:778-80.

[92] Kovar JL, Zhang J, Funke RP, Weeks DP. Molecular analysis of the acetolactate synthase gene of Chlamydomonas reinhardtii and development of a genetically engineered gene as a dominant selectable marker for genetic transformation. Plant J 2002;29:109-17.

[93] Ladygin VG. Efficient transformation of mutant cells of Chlamydomonas reinhardtii by electroporation. Process Biochem 2004;39:1685-91.

[94] Ladygin VG. The transformation of the unicellular alga Chlamydomonas reinhardtii by electroporation. Microbiology 2003;72:585-91.

[95] Niu YF, Zhang MH, Xie WH, Li JN, Gao YF, Yang WD, et al. A new inducible expression system in a transformed green alga, Chlorella vulgaris. Genet Mol Res 2011;10:3427-34.

[96] Feng S, Xue L, Liu H, Lu P. Improvement of efficiency of genetic transformation for Dunaliella salina by glass beads method. Mol Biol Rep 2009;36:1433-9.

[97] Geng DG, Han Y, Wang YQ, Wang P, Zhang LM, Li WB, et al. Construction of a system for the stable expression of foreign genes in Dunaliella salina. Acta Bot Sin 2004; $46: 342-6$.

[98] Sun GH, Zhang XC, Sui ZH, Mao YX. Inhibition of pds gene expression via the RNA interference approach in Dunaliella salina (Chlorophyta). Mar Biotechnol 2008;10:219-26.

[99] Sun Y, Yang Z, Gao X, Li Q, Zhang Q, Xu Z. Expression of foreign genes in Dunaliella by electroporation. Mol Biotechnol 2005;30:185-92.

[100] Chen HL, Li SS, Huang R, Tsai HJ. Conditional production of a functional fish growth hormone in the transgenic line of Nannochloropsis oculata (Eustigmatophyceae). J Phycol 2008;44:768-76.

[101] Li S-S, Tsai H-J. Transgenic microalgae as a non-antibiotic bactericide producer to defend against bacterial pathogen infection in the fish digestive tract. Fish Shellfish Immunol 2009;26:316-25.

[102] Sun Y, Gao XS, Li QY, Zhang QQ, Xu ZK. Functional complementation of a nitrate reductase defective mutant of a green alga Dunaliella viridis by introducing the nitrate reductase gene. Gene 2006;377:140-9.

[103] Walker TL, Becker DK, Dale JL, Collet C. Towards the development of a nuclear transformation system for Dunaliella tertiolecta. J Appl Phycol 2005;17:363-8.

[104] Kempkes MA. Pulsed electric fields for algal extraction and predator control. In: Miklavcic D, editor. Handbook of Electroporation. Cham: Springer International Publishing; 2016. p. 1-16.

[105] Rego D, Redondo LM, Geraldes V, Costa L, Navalho J, Pereira MT. Control of predators in industrial scale microalgae cultures with pulsed electric fields. Bioelectrochemistry 2015;103:60-4.

[106] Rego D, Costa L, Navalho J, Páramo J, Geraldes V, Redondo LM, Pereira MT. Pulsed electric fields applied to the control of predators in production scale microalgae cultures. In: Proceedings of the pulsed power conference (PPC), IEEE; 2013. DOI: 〈http://dx.doi.org/10.1109/PPC.2013.6627656〉.

[107] Vernhes MC, Benichou A, Pernin P, Cabanes PA, Teissié J. Elimination of freeliving amoebae in fresh water with pulsed electric fields. Water Res 2002;36:3429-38.

[108] Green MP, Fraser SA, Eckelberry ND, Pine JLS Enhancing algae growth by reducing competing microorganisms in a growth medium. United States Patent Application Publication 2012; US 2012/0329121 A1.

[109] Hunt RW, Zavalin A, Bhatnagar A, Chinnasamy S, Das KC. Electromagnetic biostimulation of living cultures for biotechnology, biofuel and bioenergy applications. Int J Mol Sci 2009;10:4515-58.

[110] Castro I, Oliveira C, Domingues L, Teixeira JA, Vicente AA. The effect of the electric field on lag phase, $\beta$-galactosidase production and plasmid stability of a recombinant Saccharomyces cerevisiae strain growing on lactose. Food Bioprocess Tech 2012;5:3014-20.

[111] Mattar JR, Turk MF, Nonus M, Lebovka NI, Zakhem HE, Vorobiev E. S. cerevisiae fermentation activity after moderate pulsed electric field pre-treatments. Bioelectrochemistry 2015;103:92-7.

[112] Hayashi Y, Sugawara K. Simultaneous coupling of phototaxis and electrotaxis in Volvox algae. Phys Rev E Stat Nonlin Soft Matter Phys 2014;89:042714.

[113] Nezammahalleh H, Ghanati F, Adams II TA, Nosrati M, Shojaosadati SA. Effect of moderate static electric field on the growth and metabolism of Chlorella vulgaris. Bioresour Technol 2016;218:700-11.

[114] Gusbeth CA, Eing C, Göttel M, Frey W. Boost of algae growth by ultra short pulsed electric field treatment. Plasma Science (ICOPS). Abstr IEEE Int Conf Plasma Sci (IOCOPS) 2013. http://dx.doi.org/10.1109/PLASMA.2013.6633325.

[115] Su L-C, Hsu Y-H, Wang H-Y. Enhanced labeling of microalgae cellular lipids by application of an electric field generated by alternating current. Bioresour Technol 2012;111:323-7.

[116] Misra R, Guldhe A, Singh P, Rawat I, Bux F. Electrochemical harvesting process for microalgae by using nonsacrificial carbon electrode: a sustainable approach for biodiesel production. Chem Eng J 2014;255:327-33.

[117] Al hattab M, Ghaly A, Hammouda A. Microalgae harvesting methods for industrial production of biodiesel: critical review and comparative analysis. J Fundam Renew Energy Appl 2015;5:154.

[118] Gao S, Du M, Tian J, Yang J, Yang J, Ma F, et al. Effects of chloride ions on electrocoagulation-flotation process with aluminum electrodes for algae removal. J Hazard Mater 2010;182:827-34.

[119] Vandamme D, Pontes SCV, Goiris K, Foubert I, Pinoy LJJ, Muylaert K. Evaluation of electro-coagulation-flocculation for harvesting marine and freshwater microalgae. Biotechnol Bioeng 2011;108:2320-9.

[120] Zenouzi A, Ghobadian B, Hejazi MA, Rahnemoon P. Harvesting of microalgae Dunaliella salina using electroflocculation. J Agr Sci Technol 2013;2013(15):879-88.

[121] Alfafara CG, Nakano K, Nomura N, lgarashi T, Matsumura M. Operating and scaleup factors for the electrolytic removal of algae from eutrophied lakewater. J Chem Technol Biotechnol 2002;77:871-6.

[122] Azarian GH, Mesdaghinia AR, Vaezi F. Algae removal by electro-coagulation process, application for treatment of the effluent from an industrial wastewate treatment plant. Iran J Public Health 2007;36:57-64.

[123] Poelman E, Pauw ND, Jeurissen B. Potential of electrolytic flocculation for recovery of microalgae. Resour Conserv Recycl 1997;19:1-10.

[124] Sridhar P, Namasivayam C, Prabharan G. Algae flocculation in reservoir water Biotechnol Bioeng 1988;32:345-7.

[125] Kim J, Ryu B-G, Kim B-K, Han J-I, Yang J-W. Continuous microalgae recovery 
using electrolysis with polarity exchange. Bioresour Technol 2012;111:268-75.

[126] Uduman N, Qi Y, Danquah MK, Forde GM, Hoadley A. Dewatering of microalgal cultures: a major bottleneck to algae-based fuels. J Renew Sustain Energy 2010;2:012701.

[127] Voldman J. Electrical forces for microscale cell manipulation. Annu Rev Biomed Eng 2006;8:425-54.

[128] Čemažar J, Miklavčič D, Kotnik T. Microfluidic devices for manipulation, modification and characterization of biological cells in electric fields - a review. J Microelectron Electron Compon Mater 2013;43:143-61.

[129] Song YX, Yang JD, Shi XF, Jiang H, Wu YB, Peng R, et al. DC dielectrophoresis separation of marine algae and particles in a microfluidic chip. Sci China Chem 2012;55:524-30.

[130] Deng Y-L, Chang J-S, Juang Y-J. Separation of microalgae with different lipid contents by dielectrophoresis. Bioresour Technol 2013;135:137-41.

[131] Hadady H, Redelman D, Hiibel SR, Geiger EJ. Continuous-flow sorting of microalgae cells based on lipid content by high frequency dielectrophoresis. AIMS Biophys 2016;3:398-414.

[132] Goettel M, Eing C, Gusbeth C, Straessner R, Frey W. Pulsed electric field assisted extraction of intracellular valuables from microalgae. Algal Res 2013;2:401-8.

[133] Donsi F, Ferrari G, Pataro G. Applications of pulsed electric field treatments for the enhancement of mass transfer from vegetable tissue. Food Eng Rev 2010;2:109-30.

[134] Knorr D, Froehling A, Jaeger H, Reineke K, Schlueter O, Schoessler K. Emerging technologies in food processing. Annu Rev Food Sci Technol 2011;2:203-35.

[135] Lebovka N, Vorobiev E, Chemat F. Enhancing extraction processes in the food industry series: contemporary food engineering. Boca Raton: CRC Press; 2011.

[136] Martin-Belloso O, Soliva-Fortuny R. Pulsed electric fields processing basics. In: Zhang HQ, Barbosa-Cánovas GV, Balasubramaniam V, Dunne CP, Farkas DF, Yuan JTC, editors. Nonthermal processing technologies for food. Hoboken: Blackwell Publishing Ltd; 2011. p. 155-75.

[137] Parniakov O, Barba FJ, Grimi N, Marchal L, Jubeau S, Lebovka N, et al. Pulsed electric field assisted extraction of nutritionally valuable compounds from microalgae Nannochloropsis spp. using the binary mixture of organic solvents and water. Innov Food Sci Emerg Technol 2015;27:79-85.

[138] Joannes C, Sipaut CS, Dayou J, Yasir SM, Mansa RF. Review paper on cell membrane electroporation of microalgae using electric field treatment method for microalgae lipid extraction. IOP Conf Ser Mater Sci Eng 2015;78:012034.

[139] Günerken E, D’Hondt E, Eppink MHM, Garcia-Gonzalez L, Elst K, Wijffels RH. Cell disruption for microalgae biorefineries. Biotechnol Adv 2015;33:243-60.

[140] Sheng J, Vannela R, Rittmann BE. Evaluation of cell-disruption effects of pulsedelectric-field treatment of Synechocystis PCC 6803. Environ Sci Technol 2011;45:3795-802.

[141] Eing C, Goettel M, Straessner R, Gusbeth C, Frey W. Pulsed electric field treatment of microalgae - benefits for microalgae biomass processing. IEEE Trans Plasma Sci 2013:41:2901-7.

[142] Zbinden MDA, Sturm BSM, Nord RD, Carey WJ, Moore D, Shinogle H, et al. Pulsed electric field (PEF) as an intensification pretreatment for greener solvent lipic extraction from microalgae. Biotechnol Bioeng 2013;110:1605-15.

[143] Coustets M, Al-Karablieh N, Thomsen C, Teissié J. Flow process for electroextraction of total proteins from microalgae. J Membr Biol 2013;246:751-60.

[144] Janczyk P, Wolf C, Souffrant WB. Evaluation of nutritional value and safety of the green microalgae Chlorella vulgaris treated with novel processing methods. Arch Zootech 2005;8:132-47.

[145] Coustets M, Joubert-Durigneux V, Hérault J, Schoefs B, Blanckaert V, Garnier JP, et al. Optimization of protein electroextraction from microalgae by a flow process. Bioelectrochemistry 2015;103:74-81.

[146] Esser AT, Smith KC, Gowrishankar TR, Vasilkoski Z, Weaver JC. Mechanisms for the intracellular manipulation of organelles by conventional electroporation. Biophys J 2010;98:2506-14.

[147] Gnapowski S, Akiyama H, Sakugawa T, Akiyama M. Effects of pulse power discharges in water on algae treatment. IEEJ Trans Fund Mater 2013;133:198-204.
[148] Lee HY, Ko YS, Lim JP, Kang JG, Kim HS, Uhm HS. Application of pulsed highvoltage discharge to algae elimination in freshwater. XXVIIth ICPIG, Eindhoven, The Netherlands, Topic number 18, 18-22 July; 2005.

[149] Su P, Feng D, Liao D, Ma Y, Xu L. Study of ballast water micro-algae inactivation using high-voltage pulsed discharge: discharge characteristics. Adv Mat Res 2012;356-360:1539-45.

[150] Gros C, Lanoisellé J-L, Vorobiev E. Towards an alternative extraction process for linseed oil. Chem Eng Res Des 2003;81:1059-65.

[151] Hwang CY, Jung S, Hwang YS, Cho BC. Lethal effects of pulsed high-voltage discharge on marine plankton and Escherichia coli. Water Air Soil Pollut 2010;213:161-9.

[152] Grimi N, Dubois A, Marchal L, Jubeau S, Lebovka NI, Vorobiev E. Selective extraction from microalgae Nannochloropsis sp. using different methods of cell disruption. Bioresour Technol 2014;153:254-9.

[153] Barba FJ, Grimi N, Vorobiev E. New approaches for the use of non-conventional cell disruption technologies to extract potential food additives and nutraceuticals from microalgae. Food Eng Rev 2015;7:45-62.

[154] Daghrir R, Igounet L, Brar S-K, Drogui P. Novel electrochemical method for the recovery of lipids from microalgae for biodiesel production. J Taiwan Inst Chem Eng 2014;45:153-62.

[155] Neto RGC, Nascimento JG, Costa MC, Lopes AC, Neto EFA, Filho CR, et al Microalgae harvesting and cell disruption: a preliminary evaluation of the technology electroflotation by alternating current. Water Sci Technol 2014;70:315-20.

[156] Florentino AP, Costa MC, Lopes AC, Neto EFA, Leitão RC, Mota CR, et al. Electroflotation by alternate current as method of microalgae harvesting and cell disruption: an advance in the feasibility of biodiesel production. In: Proceedings of the IV SOLABIAA Latin American Congress, Florianópolis, Brazil, 8-13 November; 2015.

[157] Jung K-W, Jang D, Ahn K-H. A novel approach for improvement of purity and porosity in diatomite (diatomaceous earth) by applying an electric field. Int J Miner Process 2014;131:7-11.

[158] Darra NE, Grimi N, Vorobiev E, Louka N, Maroun R. Extraction of polyphenols from red grape pomace assisted by pulsed ohmic heating. Food Bioprocess Technol 2013;6:1281-9.

[159] Kulshrestha SA, Sastry SK. Low-frequency dielectric changes in cellular food material from ohmic heating: effect of end point temperature. Innov Food Sci Emerg Technol 2006;7:257-62.

[160] Pereira RN, Rodrigues RM, Genisheva Z, Oliveira H, Freitas V, Teixeira JA, et al Effects of ohmic heating on extraction of food-grade phytochemicals from colored potato. Food Sci Technol 2016;74:493-503.

[161] Silva APFS, Costa MC, Lopes AC, Neto EFA, Leitão RC, Mota CR, et al. Comparison of pretreatment metods for total lipids extraction from mixed microalgae. Renew Energy 2014;63:762-6.

[162] Jaeschke DP, Menegol T, Rech R, Mercali GD, Marczak LDF. Carotenoid and lipid extraction from Heterochlorella luteoviridis using moderate electric field and ethanol. Process Biochem 2016;51:1636-43.

[163] Fraccola G, Fernandes BD, Geada P, Pataro G, Ferrari G, Vicente AA, Pereira RN. Enhancing extraction of food-grade pigments from the microalgae Chlorella vulgaris through application of ohmic heating. In: Proceedings of the 2016 IFT annual meeting. Chicago, USA, 16-19 July; 2016.

[164] Bahi MM, Tsaloglou MN, Mowlem M, Morgan H. Electroporation and lysis of marine microalga Karenia brevis for RNA extraction and amplification. J R Soc Interface 2011;8:601-8.

[165] Luengo E, Condón-Abanto S, Álvarez I, Raso J. Effect of pulsed electric field treatments on permeabilization and extraction of pigments from Chlorella vulgaris. J Membr Biol 2014;247:1269-77.

[166] 't Lam GP, Vermuë MH, Eppink MHM, Wijffels RH, van den Berg C. Multi-product microalgae biorefineries: from concept towards reality. Trends Biotechnol 2018;36:216-27. 